\title{
Evaluation of the Cytomorphometric Changes Observed in the Oral Mucosal Cells Exposed to Computed Tomography
}

\author{
Ritesh Srii ${ }^{1}$ \\ ${ }^{1}$ Department of Oral Pathology and Microbiology,Kathmandu University School of Medical Sciences, Dhulikhel \\ Hospital, Dhulikhel, Kavre, Nepal.
}

\begin{abstract}
Background: Radiography forms an important as well as an integral part of diagnosis which is used in various fields of medical and dental services to give an appropriate diagnosis. But, diagnostic radiations also induce some amount of damage to the cell at cytogenetic levels, depending on the dosage of the radiation administered. Materials and Methods: Study sample consisted of 15 patients who were exposed to Computed Tomography prior to treatment planning for placement of dental implants. Buccal mucosal smears were obtained pre and 10 days post radiation exposure by using a wooden tongue depressor and the contents were smeared on to clean glass slides and fixed using Biofix spray. Post fixation, these smears were stained using rapid PAP stain and viewed under compound microscope. Cytomorphometric analysis was performed using image ' $\mathrm{J}$ ' software for 50 cells. Statistical analysis was done using SPSS software. Results: Cytomorphometric analysis of the buccal mucosal cells, did show variations in the nuclear and cellular parameters, but statistical significant results were obtained in case of nuclear diameter and nuclear area only suggesting genotoxic alterations following exposure to computed tomography. Conclusion: Oral buccal mucosal cells showed significant cytomorphometric changes in the nuclear parameters after exposure to X-rays during Computed Tomography. A longitudinal study consisting of a bigger sample size is required to evaluate the long-term effects of radiation on these buccal mucosa cells.
\end{abstract}

Keywords: buccal mucosa; computed tomography; cytomorphometry; radiation.

\section{INTRODUCTION}

Over the recent decades an increasing number of people are seeking dental consultations with reasons varying from attaining relief from simple dental problems to complex cosmetic rehabilitations. Radiographic examination forms an important part in diagnosis and treatment of pathology which is used in all fields of medical and dental services. Most of these procedures require the use of different modalities of imaging techniques ranging from two dimensional to three dimensional projections.

The invention of Computed Tomography (CT) created a significant development and a boon to medical imaging techniques. Since its invention, it has been one of the most remarkable advances for providing definite diagnosis of the disease. The information obtained in a CT image varies from that in a conventional radiographic image as CT eliminates all the unwanted layers and planes using mathematical techniques and with an aid of the computer, 3D reconstruction of an image is possible from the obtained CT data. ${ }^{1}$
Many a times patients are exposed to multiple diagnostic radiations for arriving at a diagnosis. During these imaging procedures the oral mucosal cells are directly exposed to the ionizing radiations which results in alterations of the cell causing genetic mutations and chromosomal anomalies. Several factors like dose rate, administered radiation dosage, frequency of exposure to radiation and host factors like radio-sensitivity of the cell and the regenerative capability of the cell following damage, leverages the changes happening within the cell. ${ }^{2-4}$

These changes can be observed microscopically by performing a simple procedure known as exfoliative cytology, where the irradiated and exfoliated oral mucosal cells are procured, stained and viewed under microscope to study the cellular and nuclear alterations within the cell. ${ }^{5,6}$

Hence, the present study was done to evaluate the cytomorphometric changes in the oral (buccal mucosa) mucosal cells following exposure to three dimensional projections like computed tomography.

Correspondence: Dr. Ritesh Srii, Department of Oral Pathology and Microbiology, Kathmandu University School of Medical Sciences, Dhulikhel Hospital, Dhulikhel, Nepal. Email: ritesh3741@gmail.com. DOI: 10.3126/jcmsn.v14i3.19912. ORCID: orcid.org/0000-0002-3814-0936. Article received: 2018-05-15. Article accepted: 2018-06-26. 


\section{MATERIALS AND METHODS}

This is a cross sectional study done from May 2016 to May 2017 involving patients who visited the Dental department of Dhulikhel HospitalKathmandu University Hospital, Dhulikhel, Kavre, Nepal.

\section{Study Groups}

Healthy individuals between $18-40$ years of age who visited the Dental department with a chief complaint of missing teeth and requiring prosthetic replacement through dental implants were included in this study. Individuals below 18 years and above 40 years, individuals who consumed tobacco (smoked or chewed forms)/ alcohol, use of alcohol containing mouth washes, oral lesions, any debilitating diseases, and those who were exposed to X-rays in the past three months, were excluded from the study. Non-keratinized buccal epithelial cells from the oral cavity were procured from the patients who met the inclusion criteria, only after taking the informed consent from them. Buccal mucosal smears were obtained just before and ten days after exposure to radiation. The pre-exposure samples were taken as controls $(n=15)$ and post exposure samples were taken as cases $(\mathrm{n}=15)$.

\section{Study setting}

The present study was approved by the Institutional review committee of Kathmandu University School of Medical Sciences (IRC- KUSMS- No. 62/16), Dhulikhel Hospital, Dhulikhel, Kavre, Nepal. Demographic data of the patients related to their habit history, oral hygiene maintenance was recorded in a separate proforma sheet before obtaining the buccal smears. Study protocol was explained to the patients prior to taking the informed consent. Before obtaining the buccal mucosal samples, the patients were asked to rinse their oral cavity with normal tap water to remove any debris adhering to the oral mucosa. Buccal mucosal smears were obtained, and the patients were sent for Computed tomography examination using Siemens CT machine, with the system parameters set at $120 \mathrm{kv}, 340 \mathrm{mAs}$, with an effective radiation dosage of $1.5 \mathrm{mSv}$. The patients were asked to visit the Department of Oral Pathology after ten days for collection of post- radiation exposure samples.

\section{Sample collection and slide preparation}

The buccal mucosal smears were obtained using wooden tongue depressor, by scraping the buccal mucosa twice or thrice and the contents was smeared onto a clean,dry glass slide and fixed using Bio-Fix spray (Bio-Lab Diagnostics, Maharashtra). Then the slides were stained using Rapid PAP smear (Bio-Lab Diagnostics, Maharashtra) and the staining protocol was followed as recommended by the manufacturer. After staining, the slides were observed under Compound light microscope (Olympus CX-22) and the images were captured using a Digital camera (Sony DSC T-100). Cytomorphometric analysis was performed for 50 cells starting from top left-hand corner of the stained slides and the photographs were analysed using image " $\mathrm{J}$ " software as shown in Figure 1 and Figure 2. Cytomorphometric parameters analysed included nuclear diameter (ND), cell diameter (CD), nuclear diameter: cell diameter ratio (ND:CD), nuclear area (NA), cell area (CA), and nuclear area: cell area ratio (NA:CA). Finally, the data was analysed using statistical package for social sciences (SPSS) software version 20.0.

\section{RESULTS}

The numerical values obtained from the nuclear and cellular parameters were analyzed using ShapiroWilk test to assess the normality of the data. The

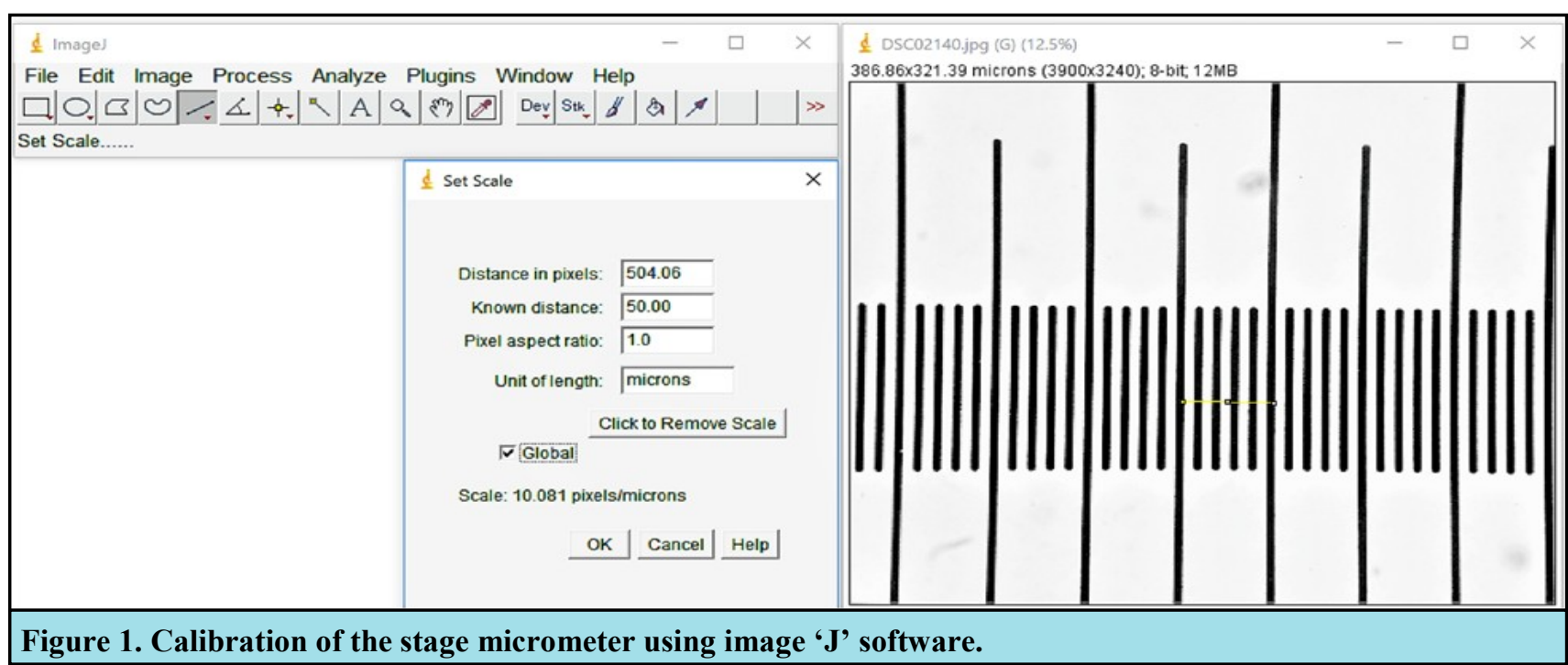




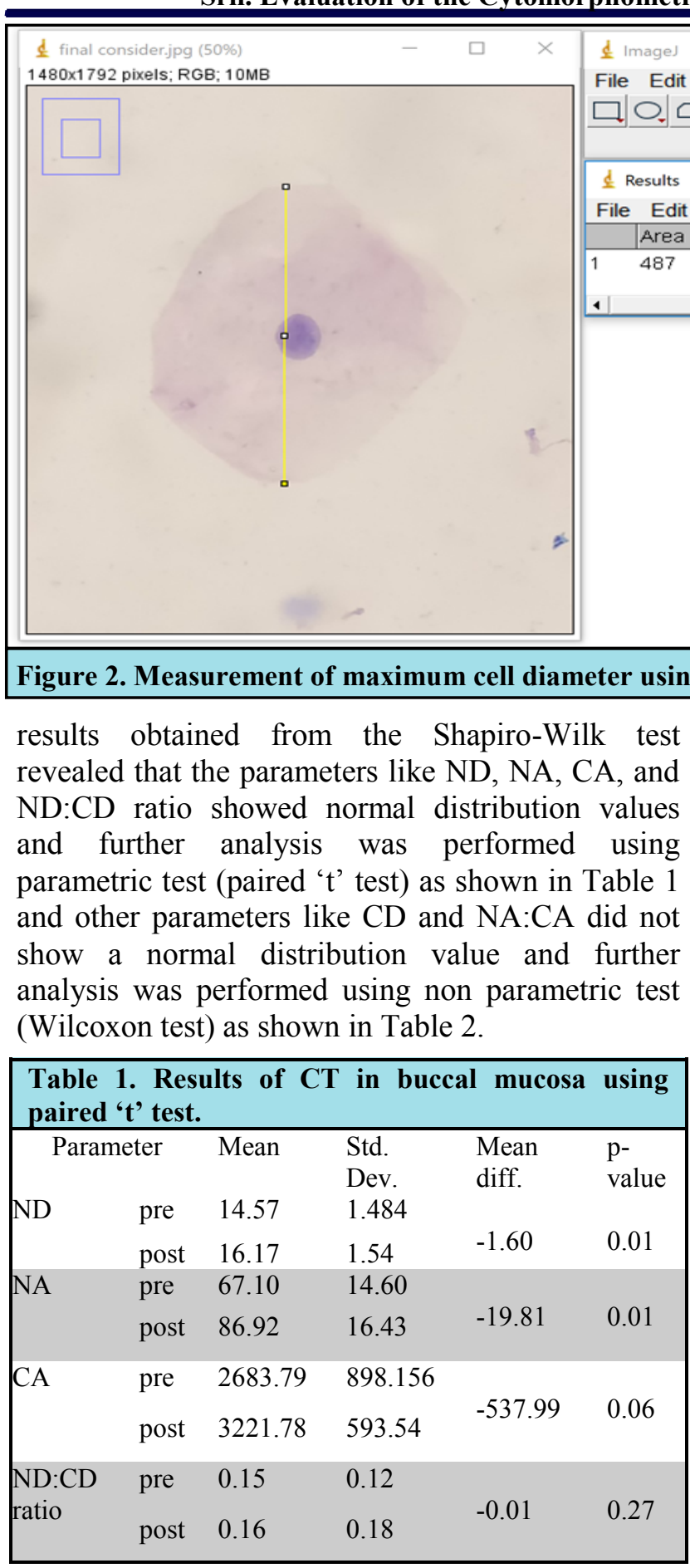

The cellular and nuclear parameters like ND, CD, ND:CD ratio, NA, and CA showed a slight increase

\begin{tabular}{|lllll|}
\hline \multicolumn{6}{|l|}{$\begin{array}{l}\text { Table 2. Results of CT } \\
\text { coxon test. }\end{array}$} \\
\hline \multicolumn{2}{|c|}{ Parameter } & Mean & Std. Dev. & p-value \\
CD & pre & 93.15 & 10.23 & \\
& post & 100.74 & 11.58 & 0.06 \\
NA:CA & pre & 0.04 & 0.05 & \\
& post & 0.03 & 0.01 & 0.41 \\
\hline
\end{tabular}

except for NA:CA ratio which showed a slight decrease suggesting an increase in the nuclear cytoplasmic ratio. A statistical significant result was obtained in case of nuclear parameters like ND and NA. An increase in nuclear parameters suggests hat there could be possible changes happening within the cells which could result in dysplasia.

\section{DISCUSSION}

Radiographic imaging plays a significant role and adds as an essential adjunct tool in addition to clinical evaluation of dental patients. Recently, many imaging modalities are available in which dental radiography plays a vital role in arriving at an appropriate diagnosis, and treatment planning. In every day practice patients are exposed to different types of available dental radiographs ranging from two dimensional to three dimensional projections or a combination of these projections. During these procedures the oral mucosa is continuously exposed to the ionizing radiations which causes cytotoxic and genotoxic changes within the irradiated cell. ${ }^{3,4}$ The term exfoliation of an epithelial cell refers to the process of loss of superficial layer of epithelium following its maturation. The study of the characteristics of these exfoliated cells are known as exfoliative cytology. It is essential to note the morphological characteristics of the cell especially of the nucleus, such as the size of nucleus, pattern of chromatin distribution and the degree of hyperchromatism; all of which display the malignant tendencies of the cell. ${ }^{6}$

The practice of oral cytology dates back over a century where the normally exfoliated cells of the body were microscopically analyzed for the 
detection and diagnosis of cancers. Papanicolaou in 1933 prepared a smear from the vaginal fluid for the detection of abnormal cells which was used in the field of gynecologic endocrinology. Later in 1943, Papanicolaou and Traut prepared a monograph which created a history on the diagnosis of uterine carcinoma using vaginal smears. Since then, exfoliative cytology has gained a widespread use, not only confined to gynecologic endocrinology but also to other various departments including that of oral cancer detection and in early diagnosis of Acquired Immunodeficiency Syndrome (AIDS). ${ }^{5-8}$

Many techniques have been employed for collecting the exfoliated cells of the oral mucosa like oral rinse technique, scraping the oral mucosa by means of a steel spatula, wooden tongue depressor, and oral CDX brushes ${ }^{9}$. In the present study, wooden tongue depressor was used as it is easy to use, disposable, leads to good amount of exfoliated sample collection and even distribution of obtained sample onto a glass slide.

According to the studies conducted by the Montgomery and Von Haam ${ }^{10}$ in 1951, they concluded that normal oral mucosal squames did not show any significant variation between the genders but, did showed significant age-related changes and changes in different sites within the oral mucosa. ${ }^{10}$ As there are no changes observed between the genders the present study did not high light the segregation between the genders.

Literature search revealed that most of the studies were done observing the cytotoxic effects in the form of morphologic alterations of the nucleus and the genotoxic alteration of the nucleus in the form of micronuclei counts. There are limited resources in the literature pertaining to the study conducted on the effects of ionizing radiation on the buccal mucosal cells exposed to CT. Hence, the results of the present study are compared with that of the other studies done on patients exposed to panoramic radiography, and in oral diseases like oral premalignant lesions and conditions, oral cancers and systemic diseases.

The present study revealed an increase in the cellular and nuclear parameters like NA, CA, ND, $\mathrm{CD}$, and ND:CD and a decrease in the NA: CA. A decrease in the NA: CA ratio means there is an alteration in the nuclear cytoplasmic ratio suggestive of changes related to the cellular atypia and likely the cell is undergoing malignant changes. ${ }^{11}$ This is in contrast with the study done by Pai et al ${ }^{12}$ who stated that there were no statistical genotoxic changes observed inpatients exposed to panoramic radiography. This could also be related to the amount of dosage administered which varies according to the technique used. As in case of conventional panoramic radiography the radiation dosage administered is $21.4 \mu \mathrm{Sv}$ compared to the radiation dosage of a digital panoramic radiography which is just half the amount of conventional panoramic radiography which varies from $5-14 \mu \mathrm{Sv}$. Even though they didn't observe any alterations at the genetic level they did observe cytomorphologic changes like nuclear pyknosis and nuclear karyolysis concluding that ionizing radiations at low doses are able to induce morphologic alterations in the nucleus.

In the present study, a significant change was observed in case of nuclear diameter and nuclear area which are in accordance to a study done by Shah et al. ${ }^{13}$ where a significant increase was noted in the NA as seen in patients with associated oral habits. Also, in concurrence with the studies done by Alberti et al, ${ }^{14}$ and Prasad et $a 1,{ }^{15}$ who have reported a significant increase in NA in diabetic patients. Similar increase has been observed in a study conducted by Ogden et $\mathrm{al}^{16}{ }^{16}$ where a significant increase was noted in NA in patients consuming alcohol.

The dosage administered in the present study is $1.5 \mathrm{mSv}$ which is comparatively high when compared to the conventional panoramic radiography. This suggests that, higher dosage of radiation is capable of inducing dysplastic changes in the oral mucosa. The present study results are in accordance to a study conducted by Ogden et al., ${ }^{17}$ which showed a significant increase in the NA in patients subjected to therapeutic radiotherapy for malignant tumors of the oral cavity.

\section{CONCLUSION}

Radiographic examinations form a part of routine investigations, which is used as an adjunct in framing diagnosis. The diagnostic radiations used in the CT radiographic technique can induce cytotoxic and genotoxic effects on the irradiated cell suggestive of a dependency upon the dosage of radiation administered. A long-term study involving a larger sample size would be required to better understand as well as to assess these radiation effects on the oral buccal mucosal cells. 


\section{REFERENCES}

1. Khambete N, Kumar R, Khambete U. Computed tomography in dentistry: Handbook of basic principles of CT \& its uses in the maxillofacial imaging. Lambert academic publishing: 2012 Mar; pg,3-4.

2. Little MP. Risks associated with ionizing radiation. Br Med Bull. 2003 Dec;68:259-75.https:// doi.org/10.1093/bmb/ldg031

3. Ghali SR, Katti G, Shahbaz S, Katti C. Cone beam computed tomography: A boon for maxillofacial imaging. J Indian Acad Oral Med Radiol. 2017 Aug;29(1):12-5. https://doi.org/10.4103/ jiaomr.JIAOMR_89_16

4. Scarfe WC, Farman AG. What is Cone-Beam CT and How Does it Work? Dent Clin North Am. 2008 Oct;52(4):707-30. https://doi.org/10.1016/ j.cden.2008.05.005. PMID:18805225.

5. Alling C, Secord R. A technique of oral exfoliative cytology. O.S, O.M \& O.P. 1964 May; 17(5): 668 676.https://doi.org/10.1016/0030-4220(64)90374-3

6. Baillie LW. Exfoliative cytology in dental practice. Aust Dent J. 1967 Dec;(6):410-4.https:// doi.org/10.1111/j.1834-7819.1968.tb03306.x.

7. Shareef BT, Ang KT NV. Qualitative and quantitative exfoliative cytology of normal oral mucosa in type 2 diabetic patients. Med Oral Patol Oral Cir Bucal. 2008 Nov;13(11):6936.PMID: 18978708

8. Dias EP, Sayed Picciani BL, De Carla Batista Santos V, Oliveira Silva-Junior G, Heffer Cantisano M, Silva-Junior A. The advantages of oral cytopathology in the early diagnosis of HIV/AIDS: Three case reports. Acta Cytol. 2012 Jul;56(4):453-6.https:// doi.org/10.1159/000335063. PMID:22846412

9. Mulki S, Shetty P, Pai P. Oral rinse as a simpler approach to exfoliative cytology: A comparative study. J Clin Diagnostic Res. 2013 Dec;7(12):30368.DOI: $\quad 10.7860 / \mathrm{JCDR} / 2013 / 6283.3843$. PMID:24551721

Citation: Srii R. Evaluation of the cytomorphometric changes observed in the oral mucosal cells exposed to computed tomographyin Nepal. JCMS Nepal. 2018;14(2):120-5.
10. Cowpe JG, Longmore RB, Green MW. Quantitative exfoliative cytology of normal oral squames; an age, site and sex-related survey. JRoyal SocietyMed. 1985 D e c ; $78: 995$ - 1004 . D O I : 10.1177 / 014107688507801204. PMID:4067983

11. White FH, Gohari K. Variations in the nuclearcytoplasmic ration during epithelial differentiation in experimental oral carcinogenesis. J Oral Pathol. 1981 Jun;10(3):164-72. PMID:6798178

12. Pai A, Sharma RC, Naik RM, Guruprasad Y. Biomonitoring of genotoxic and cytotoxic effects of gingival epithelial cells exposed to digital panoramic radiography. J Orofacial Sciences. 2012 Jan;4(2):124 -128.DOI:10.4103/0975-8844.106207

13. Shah K K, Gheena S. Comparative cytomorphometric analysis of oral mucosa in patients with diabetes, patients with associated oral habits but with apparently normal mucosa and control group. Int J Multidisciplinary Research Modern Education. 2017 Jan;3(1): 308-313.DOI:10.5958/0974360X.2017.00135.4

14. Alberti S, Spadella CT, Francischone TR, Assis GF, Cestari TM, Taveira LA. Exfoliative cytology of the oral mucosa in type II diabetic patients: morphology and cytomorphometry. J Oral Pathol Med 2003 Oct; 32:538-43.https://doi.org/10.1034/j.16000714.2003.00162.x. PMID:12969228

15. Prasad H, Ramesh V, Balamurali PD. Morphologic and Cytomorphometric analysis of exfoliated buccal mucosal cells in diabetes patients. J Cytology 2010 Oct;27(4):113-117.doi: 10.4103/0970-9371.73291. PMID:21157560.

16. Ogden GR, Wight AJ, Cowpe JG. Quantitative oral exfoliative cytology. Effect of alcohol on normal buccal mucosa. Anal Quant CytolHistol. 1999 Apr;21 (2):126-130. PMID:10560480.

17. Ogden GR, Cowpe JG, Green MW. Effect of radiotherapy on oral mucosa assessed by quantitative exfoliative cytology. J Clin Pathol. 1989 Sep; 42: 940 -3. PMID: 2507590 